\title{
HYPOCALCEMIA IN TOTAL VERSUS SUBTOTAL THYROIDECTOMY
}

\author{
Tahira Sajid, Syeda Rifaat Qamar Naqvi*, Zara Sajid, Fatima Sajid, Ismail Akbar, Muhammad Ayub Ashraf Mallhi* \\ Ayub Medical College, Abbottabad Pakistan, *Combined Military Hospital/National University of Medical Sciences (NUMS) Rawalpindi Pakistan
}

\section{ABSTRACT}

Objective: To compare the occurrence of hypocalcemia in patients undergoing subtotal and total thyroidectomy. Study Design: Comparative prospective study.

Place and Duration of Study: Surgical departments of Ayub Teaching Hospital, Abbottabad and Combined Military Hospital, Rawalpindi, from Mar 2018 to Feb 2020.

Methodology: A total of 171 patients were selected for this study and they were divided into 2 groups. Group 1 consisted of 95 patients undergoing Total thyroidectomy whereas group 2 had 76 patients undergoing Subtotal thyroidectomy. It was a comparative prospective study and the groups were made by convenience sampling. The data was analyzed by SPSS- 23 .

Results: In total thyroidectomy group Hypocalcemia was detected after 48 hours in 34 patients (35\%) while in subtotal thyroidectomy group hypocalcemia was detected in 20 patients $(28 \%)$. Tests for hypocalcemia were also done after two months of surgery and low levels were detected in 7 patients $(7.5 \%)$ who had total thyroidectomy and in 2 patients (5\%) in the group undergoing subtotal thyroidectomy. There was no significant difference in hypocalcemia after 48 hour $(p=0.22)$ and 2 months postoperatively $(p=0.6)$ between patients of Total Thyroidectomy and Subtotal Thyroidectomy.

Conclusion: Total thyroidectomy is not associated with increased risk of permanent hypocalcemia as compared to Subtotal thyroidectomy. Because of its advantages Total thyroidectomy should be the preferred surgical procedure for patients presenting with benign euthyroid multi nodular goiter.

Keywords: Hypocalcemia, Subtotal thyroidectomy, Total Thyroidectomy.

How to Cite This Article: Sajid T, Naqvi SRQ, Sajid Z, Sajid F, Akbar I, Mallhi MAA. Hypocalcemia in Total Versus Subtotal Thyroidectomy. Pak Armed Forces Med J 2021; 71 (Suppl-3): S630-633. Doi: https://doi.org/10.51253/pafmj.v1i1.7228

This is an Open Access article distributed under the terms of the Creative Commons Attribution License (https://creativecommons.org/licenses/by-nc/4.0/), which permits unrestricted use, distribution, and reproduction in any medium, provided the original work is properly cited.

\section{INTRODUCTION}

Thyroidectomy is a commonly performed procedure for different diseases of the thyroid gland.1,2 The two commonly used types of thyroidectomy are total thyroidectomy and subtotal thyroidectomy. ${ }^{3}$ When the entire thyroid gland is removed, the procedure is called total thyroidectomy; and when only 8 grams of thyroid gland is left behind on each side the procedure is called subtotal thyroidectomy. ${ }^{4}$ Subtotal thyroidectomy was previously considered the procedure of choice for the treatment of benign conditions such as goiter and thyroid adenoma as it was thought to have fewer complications. 3,5 Total thyroidectomy was the preferred procedure for the treatment of thyroid carcinoma. ${ }^{6}$ But increasingly Total thyroidectomy is preferred in benign Multinodular goiter because of its low recurrence rate, ${ }^{7}$ and not very high rate of complications. ${ }^{8}$

Calcium levels are normally maintained in the body by the action of parathyroid hormone. This is produced by the parathyroid glands which are 4 in number and are located behind the thyroid gland in the neck. Because of the close proximity of the gland

Correspondence: Ms Fatima Sajid, Medical Student, Ayub Medical College, Abbottabad Pakistan to the thyroid gland intraoperative damage to the parathyroid gland can result which can be due to devascularization of the gland, direct injury or dissection injury. ${ }^{9}$ In addition accidental removal of parathyroid gland can also occur. ${ }^{10}$

Hypocalcemia is defined as low blood calcium levels. Hypocalcemia can lead to a lot of symptoms like numbness and tingling sensation on the soles of feet, muscle twitching and cramps, perioral numbness, Trousseau's sign. headache, anxiety, depression; and rarely, if the condition gets severe, cardiac problems which includes arrhythmias or even heart failure can result. ${ }^{4}$

We aim to calculate the occurrence of persistent hypocalcemia after 2 months in our group of patient undergoing total versus subtotal thyroidectomy by performing this study.

\section{METHODOLOGY}

This comparative prospective study was carried out at the Surgical departments of Ayub Teaching Hospital, Abbottabad and Combined Military Hospital, Rawalpindi from March 2018 to February 2020, after taking informed consent from all the patients and approval from the Hospital Ethical Committee letter dated 20th February 2018. Sample size was calculated 
by using WHO sample size calculator by using $95 \%$ confidence interval, $5 \%$ error and prevalence of hypocalcemia in the first 24 hour was $49 \%$ and $63.6 \%$ after 48 hours of surgery calculated sample size was 95.1 In this study, 171 patients were included and 2 groups were made by convenience sampling. Total thyroidectomy was performed in 95 patients (group 1) and subtotal thyroidectomy was performed in 76 patients (group 2).

\section{Inclusion criteria:}

The allocation of the patient to the surgical technique, and thus to either group, was the surgeon's subjective decision in which randomization was not followed. The surgeons who performed the surgeries were consultants and had a minimum of five years' experience of doing thyroid surgeries. Efforts were made to identify the parathyroid glands in all the surgeries. Where accidentally removed the parathyroid gland was reimplanted in the sternocleidomastoid muscle following the standard procedure.

\section{Exclusion criteria:}

Patients who were having only lobectomies were not included in this study. In addition, patients having surgeries for carcinoma or recurrent multinodular goiter were excluded as the risk of damage to the parathyroid gland is greater in these cases. Preoperative calcium levels were done in each patient and all those patients who had preoperative hypocalcemia were also excluded from the study.

Calcium levels were repeated on the second postop day of all the patients. All the patients were called for follow up and their calcium level repeated after 2 months of surgery. SPSS version 23 was used for data analysis. Descriptive and inferential statistics were employed. Qualitative variables were analysed in the form of frequencies, percentages and graphs. Chi square/Fisher exact test was used, $p$-value $\leq 0.05$ was considered significant.

\section{RESULTS}

A total number of 184 patients were enrolled in the study and finally 171 patients were included in our study, 79 patients from Combined Military Hospital, Rawalpindi and 92 patients from Ayub Teaching Hospital, Abbottabad. Out of these patients 98 (57.3\%) male and $73(42.7 \%)$ were females.

One of the patients was found to be high risk for anaesthesia and refused to give consent for surgery so was excluded. One of the female patients left on the 1st postoperative day with plans of follow up in some remote area and eleven patients never returned after 2 months for investigations. So these 13 patients were removed from the final data. Mean age of patients was $46.52 \pm 5.32$ years ranging from $32-58$ years.

There were 95 patients who underwent Total thyroidectomy out of which 61 (64\%) were performed in Combined Military Hospital, Rawalpindi and 34 (36\%) were done in Ayub Teaching Hospital, Abbottabad. Out of $60(63 \%)$ were male in $35(37 \%)$ were female. Out of 60 total thyroidectomy patients in Combined Military Hospital, Rawalpindi 48 (80\%) patients male and $12(20 \%)$ were female and in Ayub Teaching Hospital, Abbottabad 13 (37\%) were male and 22 (63\%) were female show in Figure-1.



Figure-1: Total thyroidectomy cases.

There were 76 subtotal thyroidectomy patients of which 18 (23.6\%) and 58 (76.4\%) were done in Combined Military Hospital, Rawalpindi and Ayub Teaching Hospital, Abbottabad, respectively. Out of 38 (50\%) were male and $38(50 \%)$ were females. Out of 38 subtotal thyroidectomy patients in Combined Military Hospital, Rawalpindi 10 (26\%) were male and 28 (74\%) were female and in Ayub Teaching Hospital, Abbottabad $8(21 \%)$ were male and $30(79 \%)$ were female show in Figure-2.

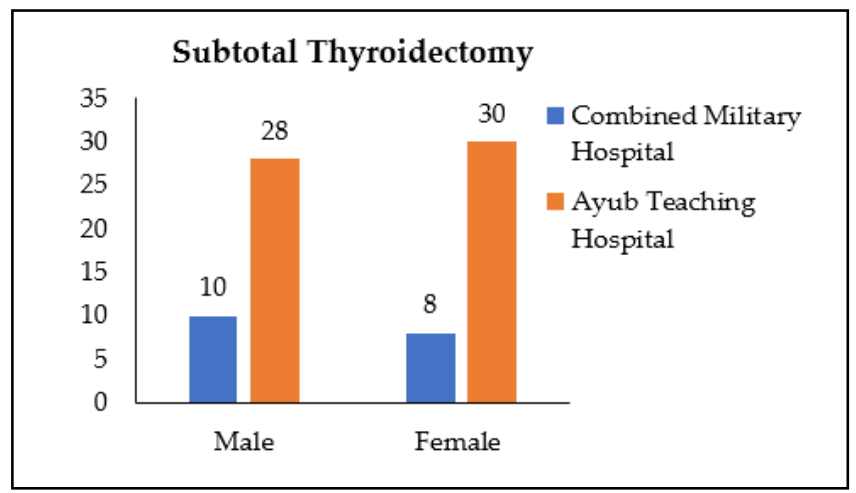

Figure-2: Subtotal thyroidectomy cases.

In total thyroidectomy group Hypocalcemia was detected after forty eight hours in 34 patients (35\%) 
while in subtotal thyroidectomy group hypocalcemia was detected in 20 patients $(28 \%)$. There was no statistically significant difference between these two values $(p=0.22)$ as shown in Table-I.

Table-I: Comparison of hypocalcemia after 48 hours between total thyroidectomy and subtotal thyroidectomy.

\begin{tabular}{|c|c|c|c|}
\hline \multirow[b]{2}{*}{ Hypocalcemia } & \multicolumn{2}{|c|}{ Study Groups n (\%) } & \multirow[b]{2}{*}{$\begin{array}{c}p- \\
\text { value }\end{array}$} \\
\hline & $\begin{array}{c}\text { Total } \\
\text { Thyroidectomy } \\
(\mathbf{n}=95)\end{array}$ & $\begin{array}{c}\text { Subtotal } \\
\text { Thyroidectomy } \\
(\mathbf{n}=74)\end{array}$ & \\
\hline $\begin{array}{l}48 \text { Hours } \\
\text { Yes } \\
\text { No }\end{array}$ & $\begin{array}{l}34(35) \\
61(65)\end{array}$ & $\begin{array}{l}20(28) \\
54(72)\end{array}$ & 0.22 \\
\hline
\end{tabular}

Tests for Hypocalcemia were also done after two months of surgery and low levels were detected in 7 patients $(7.5 \%)$ who had Total thyroidectomy and in 2 patients $(5 \%)$ in the group undergoing subtotal thyroidectomy. Again there was no significant difference in hypocalcemia after 2 months postoperatively $(p=0.6)$ between patients of total thyroidectomy and subtotal thyroidectomy as shown in Table-II.

Table-II: Comparison of hypocalcemia after 2 months between total thyroidectomy and subtotal thyroidectomy.

\begin{tabular}{|c|c|c|c|}
\hline \multirow[b]{2}{*}{ Hypocalcemia } & \multicolumn{2}{|c|}{ Study Groups n (\%) } & \multirow[b]{2}{*}{$\begin{array}{c}p- \\
\text { value }\end{array}$} \\
\hline & $\begin{array}{c}\text { Total } \\
\text { Thyroidectomy } \\
(\mathrm{n}=95)\end{array}$ & $\begin{array}{c}\text { Subtotal } \\
\begin{array}{c}\text { Thyroidectomy } \\
(\mathrm{n}=74)\end{array}\end{array}$ & \\
\hline $\begin{array}{l}2 \text { Months } \\
\text { Yes } \\
\text { No }\end{array}$ & $\begin{array}{c}7(7.5) \\
88(92.5)\end{array}$ & $\begin{array}{c}4(5) \\
70(95)\end{array}$ & 0.6 \\
\hline
\end{tabular}

\section{DISCUSSION}

Total thyroidectomy has a clear advantage over subtotal thyroidectomy in terms of a lower recurrence rate so this is the preferred surgical method in patients needing thyroidectomy worldwide. ${ }^{7}$ Research is going on to assess different complications of the procedure and whether the incidence of those complications in the two methods of thyroidectomy is similar or there is significant variation. Hypocalcemia is the most common complication following thyroidectomy. ${ }^{11}$ Hypocalcemia can lead to difficulty in breathing or seizures but these are very rare as hypocalcemia can be easily treated by calcium supplements. ${ }^{12}$ Hypocalcemia can be either transient or permanent. ${ }^{13}$ It can present secondary to hypoparathyroidism which occurs post-operatively as a result of either trauma, compromise in vascular supply or removal of the parathyroid glands altogether. ${ }^{2}$

In our present study project, we compared the two types of thyroid surgery as to which of them is more likely to result in permanent hypocalcemia in the patients.
Various studies have been done on different groups of patients to calculate the complication rate in these surgeries. Studies have been done for malignant cases, ${ }^{14}$ cases which needed lymph node dissections and in hyperthyroid patients 9 with varying results. A study was done on Chinese population and it was noted that incidence of postoperative hypocalcemia and hypoparathyroidism was related to the indication for which the surgery was done and was directly related to the duration of the surgery. ${ }^{9}$ As malignancy or hyperthyroidism and revision surgery were in our exclusion criteria so we did not assess these parameters in our study.

The age of the patients on whom this study was done was 32-58 years with a mean of $46.52 \pm 5.32$ years. The usual mean age of patients on whom these surgeries are being performed for benign multinodular goiter vary from 33.415 to 49.71 according to studies done by Sugino et al in Japan and Azadbakht et al in Iran.

Around the world females have a higher incidence of benign multinodular goiter so the females undergo these surgeries more commonly. The male to female ratio in a study was 1:1.6. 1 In our study the male to female ratio is 1.3:1 which is different as compared to most of the comparable studies. The reason for this difference in male to female ratio is the source of data that we collected. A large part of our data was collected from $\mathrm{CMH}$ Rawalpindi which being a facility for the armed forces personnel caters for the soldiers. Therefore the patients which are received and treated here are mostly males. The same case was seen in a similar study done in $\mathrm{CMH}$ Rawalpindi where the female to male ratio was not according to the international studies due to majority of inpatients being male in this setup. ${ }^{5}$

We had 2 groups of patients in our study. Group 1 had undergone total thyroidectomy while group 2 had subtotal thyroidectomy performed for treatment. The incidence of hypocalcemia on 2 nd day of surgery in group 1 was $34 \%$ while it was $28 \%$ in group 2 . This difference was statistically insignificant as is seen in a lot of latest research work done around the world. In one study done in 2013 in Turkey, ${ }^{16}$ it was shown that hypocalcemia was 3.16 fold more common in patients undergoing total thyroidectomy as compared to the subtotal thyroidectomy group but their study did not exclude cases of hyperthyroidism, repeat thyroidectomies, malignant cases and cases which needed lymph node dissections. In 2015 another study 3 was done on 
a wider scale in Turkey and it showed no difference in the incidence of postoperative hypocalcemia in patients undergoing subtotal versus total thyroidectomy.

The occurrence of permanent hypocalcemia as shown by tests done 2 months postoperatively was $7.5 \%$ in group 1 and $5 \%$ in group 2 patients which is again comparable to the international studies done in different areas of the world where thyroid diseases are endemic like Turkey, ${ }^{17}$ and India. ${ }^{7}$ In other studies done in 2019 and 2020 total thyroidectomy was identified as being an important risk factor in the development of persistent postoperative hypocalcemia.15,18 While in a meta analysis done on 1078 patients it was concluded that there is no statistically significant difference in the incidence of permanent hypocalcemia in patients undergoing total versus subtotal thyroidectomy. ${ }^{8}$

Our study along with most of the research work done worldwide showed insignificant difference in the incidence of permanent hypocalcemia following total versus subtotal thyroidectomy for benign euthyroid multi nodular goiter.

\section{CONCLUSION}

We concluded that Total thyroidectomy is not associated with increased risk of permanent hypocalcemia as compared to subtotal thyroidectomy. Because of its advantage over subtotal thyroidectomy having lower chances of recurrence of disease, Total thyroidectomy should be the preferred surgical procedure for patients presenting with benign euthyroid multi nodular goiter.

\section{Conflict of Interest: None.}

\section{Authors' Contribution}

TS: Literature review, SRQN: Proof reading, ZS: Literature review, FS: Literature review, IA: Data collection, MAAM: Data collection.

\section{REFERENCES}

1. Azadbakht M, Emadi-Jamali SM, Azadbakht S. Hypocalcemia following total and subtotal thyroidectomy and associated factors. Ann Med Surg 2021; 5(1): 102417.

2. Khairy GA, Al-Saif A. Incidental parathyroidectomy during thyroid resection: incidence, risk factors, and outcome. Ann Saudi Med 2011; 31(3): 274-278.

3. Ciftci F, Sakalli E, Abdurrahman I. Total versus bilateral subtotal thyroidectomy for benign multi-nodular goiter. Int J Clin Exp Med 2015; 8(3): 4596.
4. Association AT. Risk of hypoparathyroidism after total thyroidectomy. American Thyroid Association. 2018 [Internet]. Available from: https://www.thyroid.org/patient-thyroidinformation/ct-for-patients/may-2018/vol-11-issue-5-p-6-7/ [Assessed 2021 Aug 8],

5. Sajid T, Naqvi SR Q, SS QN, Shukr I, Ghani R. Recurrent Laryngeal Nerve Injury In Total Versus Subtotal Thyroidectomy. J Ayub Med Coll, Abbottabad 2016; 28(3): 559-561.

6. Bhattacharyya N, Fried MP. Assessment of the morbidity and complications of total thyroidectomy. Arch Otolaryngol Head Neck Surg 2002; 128(4): 389-392.

7. Padur AA, Kumar N, Guru A, Badagabettu SN, Shanthakumar SR, Virupakshamurthy MB, Patil J. Safety and effectiveness of total thyroidectomy and its comparison with subtotal thyroidectomy and other thyroid surgeries: a systematic review. J Thyroid Res 2016; 2016(2): 7594-7615.

8. Li Y, Li Y, Zhou X. Total thyroidectomy versus bilateral subtotal thyroidectomy for bilateral multinodular nontoxic goiter: a metaanalysis. Orl 2016; 78(3): 167-175.

9. Wang YH, Bhandari A, Yang F, Zhang W, Xue LJ, Liu HG, et al. Risk factors for hypocalcemia and hypoparathyroidism following thyroidectomy: a retrospective Chinese population study. Cancer Manag Res 2017; 9(2): 627-630.

10. Du W, Fang Q, Zhang X, Cui M, Zhao M, Lou W. Unintentional parathyroidectomy during total thyroidectomy surgery: A single surgeon's experience. Med (Baltimore) 2017; 96(11): e6411.

11. Chahardahmasumi E, Salehidoost R, Amini M, Aminorroaya A, Rezvanian H. Assessment of the early and late complication after thyroidectomy. Adv Biomed Res 2019; 8(2): 14-18.

12. Shomon M. Post-thyroidectomy side effects and recovery [Internet]. Verywell Health. 2020. [Internet] Available from: https://www.verywellhealth.com/recuperating-after-thyroidsurgery-3233273 [Assessed 2021 Aug 8],

13. Abou-Amra M, Abdel-Rahman YO. Effect of bilateral truncal inferior thyroid artery ligation on parathyroid function. AlAzhar Assiut Med J 2011; 9(2): 1687-1693.

14. Li Y, Liu Y, Huang Y, Liu J, Chu J. Total versus subtotal thyroidectomy for differentiated thyroid carcinoma and their influence on related indexes. Int J Clin Exp Med 2020; 13(10): 8007-8013.

15. Sugino K, Nagahama M, Kitagawa W, Ohkuwa K, Uruno T, Matsuzu K, et al. Change of surgical strategy for Graves' disease from subtotal thyroidectomy to total thyroidectomy: a single institutional experience. Endocr J 2019; 66(2): 181-186.

16. Kalyoncu D, Gönüllü D, Gedik ML, Er M, Kuroğlu E, İğdem AA, et al. Analysis of the factors that have an effect on hypocalcemia following thyroidectomy. Turk J Surg 2013; 29(4): 171-175.

17. Colak T, Akca T, Kanik A, Yapici D, Aydin S. Total versus subtotal thyroidectomy for the management of benign multinodular goiter in an endemic region. ANZ J Surg 2004; 74(11): 974-978.

18. Sharma PK. Complications of thyroid surgery [Internet]. Practice Essentials, Overview, Bleeding. Medscape; 2021 Available from: https://emedicine.medscape.com/article/852184overview\#: :te $\mathrm{xt}=$ Potential\%20major\%20complications \%20of\%20thyroid,image $\%$ 20below)\%2C\%20and\%20infection. [cited 2021Aug8]. 